\title{
EL HADĪ T DE “EL PROFETA MUHAMMAD Y EL NIÑO HUÉRFANO", EN EL MANUSCRITO MUDÉJAR-MORISCO DE OCAÑA, COTEJADO CON LA VERSIÓN ALJAMIADO-MORISCA EN EL MANUSCRITO II/3226 DE LA BIBLIOTECA REAL EN MADRID
}

Iris Hofman Vannus*

\section{INTRODUCCIÓN}

En 1969, durante unas obras de restauración en la Casa de la Encomienda en Ocaña (Toledo), se hallaron nueve manuscritos y unos objetos en una alacena oculta en la pared ${ }^{1}$. Uno de estos manuscritos, el Manuscrito mudéjar-morisco de Ocaña, formaba parte de este sorprendente hallazgo y ha sido traducido, estudiado y editado por la autora de este artículo².

* Investigadora y escritora. Madrid.

1. Para una descripción de los manuscritos y los objetos hallados en Ocaña, cf. I. HofMAN VANNUS, «El manuscrito mudéjar-morisco de Ocaña», publicado en la revista Anaquel de estudios árabes, vol. 14 (2003), pp. 119-127. La primera noticia de los manuscritos se debe a J. AlBARRACín NAVARRO y J. MARTíNEZ RUIZ, «Libros árabes, aljamiados, mudéjares y bilingües descubiertos en Ocaña (Toledo)», Revista de Filología Española, LV (1972) [1973], pp. 63-66. Otro de los nueve manuscritos fue parcialmente traducido (fols. 1r- 30r) y editado por J. AlBARRACín NAVARRO y J. Martínez Ruiz, Medicina, farmacopea y magia en el "Misceláneo de Salomón", Granada, 1987.

2. I. Hofman VANnUs, Historias religiosas musulmanas en el Manuscrito mudéjar-morisco de Ocaña. Edición y estudio. Tesis doctoral presentada en la Universidad Complutense de Madrid el día 31 de octubre de 2001. Publicada en CD-ROM en 'Tesis doctorales UCM 2001', Humanidades, Facultad de Filología, con ISBN: 84-669-1913-9. 
El manuscrito consta de ciento ochenta y nueve folios, escritos por ambas caras menos el último y en dialecto árabe-andalusí, con grafía magrebí, con un ductus fluido, apresurado y descuidado, lo que indica que el amanuense era una persona de cierta cultura y muy familiarizado con el texto y con el qalam. Generalmente, hay once líneas por folio y se observan múltiples y diversos signos codicológicos. Se ha utilizado tinta negra, aunque ahora desvaída hacia marrón, para la grafía; tinta roja para remarcar y resaltar ciertas palabras del texto y, alrededor del título, para realzar toscamente el frontíspice (fol. 2r) con un sol, un šams (¿representando al profeta Muhammad?) y con un marco geométri$\mathrm{co}$, tinta verde, tinta roja y tinta amarilla, ¿imitando oro que el pobre bolsillo del escribidor no pudo costear? Es de pequeñas dimensiones, $10 \times 7 \mathrm{~cm}$, lo que facilitaba su uso y su transporte en cualquier bolsillo o faltriquera. La autoría es incierta y la datación se puede situar alrededor de 1450 d. C., a juzgar por el duc$t_{u s}{ }^{4}$ y la calidad de papel, tosca a pesar de que éste contiene en veintitrés folios una $\mathrm{u}$ otra filigrana. El manuscrito ha sufrido varias encuadernaciones, no del todo y no siempre acertadas. Contiene glosas, marginales y de todo tipo, numerosas en árabe, otras en romance y dos en aljamiado. Encuadernada junto al manuscrito se halla una carta escrita en árabe ${ }^{5}$. Si bien el manuscrito ha sido hallado en Ocaña, puede que su factura se haya efectuado en otro lugar de la Península Ibérica y que su procedencia exacta sea aún una conjetura sin resolver. Se halla en buen estado gracias a su ocultamiento de más de quinientos años, apartado de luz, agua, alimañas e insectos u otros parásitos dañinos. El manuscrito mudéjar-morisco, junto a sus otros ocho hermanos manuscritos, distintos entre sí en cuanto a tamaño y aspecto, forma parte de una colección particular y está bien conservado de las inclemencias ambientales.

El Manuscrito mudéjar-morisco de Ocaña es un breviario musulmán, utilizado como tal por el líder espiritual de la comunidad musulmana, generalmente un alfaquí ${ }^{6}$, para instruir a sus fieles acerca de sus preceptos y deberes religiosos para obrar rectamente, abstenerse de hacer lo prohibido y, de este modo, alcanzar el paraíso después de la muerte. Para tal fin, el alfaquí se ser-

3. Para el dialecto árabe-andalusí, véase F. CORRIEnTE, A Grammatical Sketch of the Spanish Arabic Dialect Bundle, Madrid, 1977.

4. J. von KarabaceK, Das Arabische Papier, ensayo publicado como edición especial de los tomos II y III de la revista Mittheilungen aus der Sammlung der Papyrus Erzherzog Rainer, Verlag der Kaiserl., Konigl., Hof- und Staatsdruckerei, Viena, 1887, p. 4: “. .zumal ja die Schreibschulung der einen Epoche stets eine constante charakteristische Eigenart von der andern ausweist... ".

5. El contenido de la carta ha sido publicado por M.J. VIGUERA MoLínS, «Les mudéjars et leurs documents écrits en arabe», en la Révue du Monde Musulman et de la Méditerranée, 63-64, 1-2 (1992), pp. 155-161.

6. Acerca de la posición social y la cultura literaria de los alfaquíes en la Península Ibérica, cf. A. LABARTA y J.C. ESCRIBANO, «Las bibliotecas de dos alfaquíes borjanos», en Anaquel de estudios árabes, 11 (2000), pp. 355-367; F. CORRIENTE CÓRDOBA, Relatos píos y profanos del ms. aljamiado de Urrea del Jalón, Prólogo de María J. Viguera, Zaragoza, 1990, Introducción, p. 25. 
vía de los relatos e historias contenidos en un breviario como éste, para ilustrar mediante la exposición de la conducta paradigmática de los profetas cómo se había de comportar el buen musulmán para alcanzar el paraíso, al-ŷanna ${ }^{7}$ y mediante la exposición de la conducta errónea de los hombres comunes, sea hombre o sea mujer, cómo el fiel musulmán tenía que abstenerse del mal, si no quería ir al infierno, al fuego eterno, al-nār .

El Manuscrito mudéjar-morisco de Ocaña lleva en el frontíspice (fol. 2r) por título escrito en árabe "Libro compuesto y seleccionado de hadices y relatos de los ulemas y de los profetas, la paz sea con ellos".

En el presente artículo se ofrece un $h a d \underline{i t}^{8}$, cuyos protagonistas le dan el título El profeta Muhammad y el niño huérfano. Aunque ya se han encontrado versiones de este hadìt en otros manuscritos, aljamiado-moriscos ${ }^{9}$ como el manuscrito aljamiado-morisco II/3226, conservado en la Biblioteca Real del Palacio Real de Madrid ${ }^{10}$ y titulado "La leyenda del alcázar de oro" de la que forma parte (fols. 58v-63v) la historia de El profeta Muhammad y el niño huérfano, de lo que se trata aquí es de una versión escrita en el dialecto árabe-andalusí, procedente de El manuscrito mudéjar-morisco de Ocaña ${ }^{11}$ y que es probablemente anterior a la versión aljamiado-morisca del Ms. II/3226 de la Biblioteca

7. I. HofmAn VANNUS, «Jesús y la calavera», en Crónicas AZAHAR, Revista de la actualidad cultural, 2 (enero 2004), pp. 4-16, con foto de Ms. Oc (fols. 1v-2r). La foto se debe a la cortesía de D. Rafael del Águila y Dña. Luisa Tejerina; I. HofMAN VANNUS, «La figura de Jesús en el Manuscrito mudéjar-morisco de Ocaña», Encuentro islamo-cristiano, 396 (abril 2005), pp. 2-11 (monografía); I. Hofman VANnUS, «El Trono (de Dios), en el Manuscrito mudéjar-morisco de Ocaña», en 'Ilu, Revista de Ciencias de las religiones, vol. 9 (2004), pp. 91-100; I. HofMAN VANNUS, «Referencias literarias al dirham y al dīnār en el Manuscrito mudéjar-morisco de Ocaña», Anaquel de estudios árabes, 15 (2004), pp. 165-174.

8. Sobre la definición de hadīt, cf. A. JefFerY, A Reader on Islam, 's-Gravenhage, 1962, pp. 79-80; M. ABumalHAm (coord.), Textos fundamentales de la tradición religiosa musulmana, Barcelona, 2005, pP. 37-39.

9. F. Corriente Córdoba, Relatos píos y profanos del Ms. aljamiado de Urrea del Jalón, pp. 268-270, donde se recoge el hadīt XXIII. L-alhadīt de laísiyerpe. Este hadīt se halla en los folios 180v-182r de dicho manuscrito aljamiado, que fue encontrado el 21 de julio de 1984, según consta en el Prólogo, p. 10. Otras referencias a este hadìt, cf. Prólogo, pp. 43-44 y notas 178 y 179, con referencia a Ms. II/3226 de la Biblioteca Real de Madrid. Las versiones aljamiadas-moriscas "Ms. Urrea del Jalón" y Ms. II/3226 corren muy en paralelo con el texto escrito en árabe andalusí del Ms. de Ocaña. No es en absoluto descabellado pensar que el Ms. de Ocaña precede a las versiones aljamiadas.

10. Acerca de los manuscritos moriscos conservados en la Biblioteca Real del Palacio Real en Madrid y con mención específica al Ms. II/3226-aljamiado, cf. R. CASTRILLO MÁRQUEZ, «Un manuscrito de tema morisco en la biblioteca del Palacio Real en Madrid», Anaquel de estudios árabes, 1 (1990), pp. 35-48, especialmente pp. 35 y 41.El Ms. II/ 3226 - aljamiado es de procedencia aragonesa y fue hallado en 1728 en Ricla (Zaragoza). Se trata de un manuscrito del s. XVI. Hay referencias bibliográficas de Eduardo Saavedra (1878), González Palencia (1915) y de Rafaela Castrillo Márquez (1989).

11. A partir de ahora se va a referir a El Manuscrito mudéjar-morisco de Ocaña como Ms. Oc, tal como se ha hecho en la Tesis doctoral. 
Real y de grafía torpe, a juzgar por el ductus del manuscrito mudéjar-morisco de Ocaña, más suelto en su grafía magrebí y que presenta numerosos detalles descriptivos y un estilo narrativo más fluido. De ambas versiones, la mudéjar-morisca y la aljamiado-morisca, se ofrece en el presente artículo la traducción al castellano; primero, la versión mudéjar-morisca de Ms. Oc (fols. 149v157r) y, a continuación, la aljamiado-morisca II/3226 (fols. 58v-63v).

\section{OBSERVACIONES}

La gran semejanza entre el texto escrito en árabe andalusí de El profeta Muhammad y el niño huérfano en el Manuscrito mudéjar-morisco de Ocaña y los textos aljamiados hallados en Urrea del Jalón (Ms. aljamiado de Urrea del Jalón) y en Ricla (Ms. II/3226) inducen a pensar en un origen geográfico común en cuanto a su composición literaria y su factura material: Aragón.

Si bien los hadices son de origen muy antiguo y su trama esencial apenas varía, así como sus protagonistas principales suelen ser los mismos y sus circunstancias persisten, la composición encontrada en estos tres manuscritos es más reciente en el tiempo: probablemente el s. XV para Ms. Oc y s. XVI para Ms. Urrea de Jalón ${ }^{12}$ y Ms. II/3226 Real Biblioteca de Madrid. Las divergencias estilísticas se deben, sobre todo, a los efectos de la transmisión oral ${ }^{13}$, rasgo común de la época de su composición literaria, hecho que permitía añadir detalles más o menos pintorescos para enfatizar la personalidad de los principales actores, a pesar de contar con una cadena de transmisores más o menos fiables para cada hadīt, colecciones prestigiosas y, mucho más tarde, a pesar de disponer de breviarios parecidos al Manuscrito mudéjar-morisco de Ocaña para la instrucción doctrinal de los fieles. También observamos que paulatinamente se van perdiendo ciertos detalles pormenorizados e, incluso, la fluidez narrativa del propio relato a causa de la dilatación en el tiempo durante su transmisión literaria de generación en generación y a través de diferentes ámbitos geográficos.

Se supone que los textos fueron plasmados sobre el papel por copistas mudéjares y moriscos y que la grafía descuidada de Ms. Oc se debe seguramente a las prisas para escribir el texto, a pesar de las buenas intenciones de “aquella desventurada gente mora, española por el nacimiento, por su entra-

12. Aunque Ms. Urrea del Jalón "no lleva fecha ninguna... ha de fecharse con posterioridad al decreto de conversión al cristianismo de los mudéjares, aplicado en Aragón desde 1526", cf. F. CORRIENTE CóRDOBA, op. cit., Introducción, pp. 12-13.

13. F. GuILlén Robles, Leyendas moriscas, Estudio preliminar $\mathrm{M}^{\mathrm{a}}$ Paz Torres (edición facsímil, vols. I, II, III), Granada, 1994, vol. I, pp. 8-9. El texto original de las Leyendas moriscas fue dado a la imprenta en 1885-1886 en Madrid, según anota Ma Paz Torres en su 'Estudio preliminar', p. LX. 
ñable amor á nuestra tierra, por sus condiciones de carácter, por sus virtudes, y hasta por sus defectos" ${ }^{\prime 14}$. La grafía más torpe de los textos aljamiados se debe al durísimo e implacable proceso de aculturación de los moriscos del s. XVI, los que, a pesar de todos los peligros y todas las presiones políticas y religiosas, se aferraban a sus señas de identidad, su religión, su lengua, su grafía arábiga, unidas en un único y primer libro escrito en árabe, el Corán ${ }^{15}$, razón de su ser y su vivir como buenos musulmanes.

Y ¿quién fue "el célebre escritor árabe Abdallá vulgarmente llamado Alrriblí" mencionado por Pascual Madoz en su Diccionario ${ }^{16} \cdot{ }^{1}$ Puede haber sido este 'célebre Alrriblí' la persona, el autor, que compuso algún libro recopilando y seleccionando "los hadices y los relatos de los ulemas y de los profetas", tal como reza el título en árabe andalusí del Manuscrito mudéjar-morisco de Ocaña y que este autor hubiera podido transmitir y proporcionar los textos primitivos de "relatos píos y profanos" que circulaban entre los habitantes musulmanes de Aragón? ¿Quién era este autor y cuándo vivió o, acaso, fue otra persona el autor/amanuense de dichos textos?, éstas son las preguntas que quedan por resolver con el fin de poder desentrañar el enigma de la autoría y la procedencia de estos textos religiosos musulmanes.

Otro factor que pudiera concurrir para resolver las dudas acerca de la datación certera de los manuscritos en cuestión es la disciplina ancillaria de fechar la factura de su soporte material, el papel, mediante los análisis microscópicos y químicos. Para tal fin, sería necesario y suficiente proporcionar diminutas muestras del papel utilizado en los manuscritos a los científicos de instituciones especializadas en tales hazañas.

Quizá futuras investigaciones en estas direcciones podrán resolver los problemas inherentes, con el fin de conocer más y mejor nuestro acervo cultural común.

\section{TEXTOS}

\section{El PROFETA MUHAMMAD Y EL NIÑO HUÉRFANO EN EL MANUSCRITO MUDÉJAR-MORISCO DE OCAÑA (FOLS. 149V-157R)}

Nos han llegados noticias de que el Profeta, Dios lo bendiga y salve, estaba sentado con un grupo de sus amigos, cuando se puso a reflexionar acerca de la

14. F. GuILlén Robles, op. cit., p. 10.

15. A. JeFFERY, Foreign vocabulary of the Qur'an, 1937, Baroda (India), 1938, Introduction, p. vii.

16. P. MADOZ, Diccionario geográfico-estadístico-histórico de España y sus posesiones de Ultramar, Madrid, 1846, Tomo XIII, p. 470. 
otra vida y la inconstancia del mundo y empezó a llorar amargamente y todos que estaban con él lloraron. Dijo el Profeta, Dios lo bendiga y salve: “iEmigra$\operatorname{dos}^{17}$ y Aliados ${ }^{18}$ ¡ ¡Venid a reflexionar acerca del mundo! ¡Comerciad con la gente y la gente con vosotros!”. Ellos le preguntaron: “¿Enviado de Dios! ${ }^{19}$. ¿Qué tipo de negocio haremos / / 150r con la gente y la gente con nosotros?". [Les] contestó el Profeta, Dios lo bendiga y salve: "Saludad a la gente y la gente os saludará. Quien devuelve el saludo, da buena obra por buena obra y quien no devuelve el saludo, pues se le escribirán [en su librillo] trescientas malas acciones y se le borrarán trescientos setenta buenas acciones. Quien devuelve el saludo, se le regalarán las buenas acciones. Quien no devuelve el saludo se le regalarán malas acciones. Si encontrarais un cautivo, lo soltaréis; si encontrarais un huérfano, lo acogeréis o si encontrarais una persona desnuda, la cubriréis y si encontrarais un pobre, lo regalaréis lo que / / 150v os ha regalado Dios. Si hubiera con vosotros alguna cosa... [ilegible en Ms. Oc]...sino quien menciona a Dios, el Altísimo". Así dijo.

Mientras ellos estaban así, se pusieron a andar por las estrechas calles de la medina, cuando se toparon con un muchacho ${ }^{20}$ que había puesto sus manos en sus rodillas, mientras las lágrimas fluían por sus mejillas. Le dijo el Profeta, Dios lo bendiga y salve: “¿Qué te hace llorar, hijito?” [El muchacho] contestó: "Amigo, Enviado de Dios, lloro por mi orfandad"21. Le preguntó el

17. Los Emigrados, los Muhâŷirūn, son los habitantes de La Meca, que acompañaban a Muhammad en su huida hacia Yatrib (más tarde llamada Madinat al-nabī, Medina), ante la ira, el acoso y la hostilidad de los mekíes, en $622 \mathrm{~d}$. C. A partir de esta fecha comienza a computar la era musulmana. En Ms. Oc se nombra a los Emigrados y los Aliados juntos. Cf. Corán III, 185, que alude a este momento de la huida, aparte de otras menciones.

18. Los Aliados, los Anșār, es el epíteto dado a los miembros del clan al-Aws y del clan al-Jazraŷ, que formaban parte de la Banū Qayla. Estos habitantes de Yatrib (cf. Corán XXXIII, 13: “...ya ahla Yatriba...") ayudaron a Muhammad en su lucha contra los de La Meca. Formaban un $75 \%$ de las fuerzas musulmanes en la batalla de Badr $(2$ H/ 624 d. C.). Más tarde apoyaban a 'Alī; luego a los 'Abbāsíes, Cf. Encyclopédie de l' Islam, I, pp. 514-515, art. W. M. Watt. En Ms. Oc (121r, 122v, 150r) se les nombra siempre junto a los Emigrados, los Muhāŷirūn (q.v.).

19. El término 'Enviado', en árabe rasūl, en su sentido profano significa 'mensajero'. En su sentido religioso significa 'apóstol', 'Enviado'. Según el Corán, existe una relación profunda entre el Enviado y su gente, su Umma. A cada Umma, Dios manda sólo un Enviado (Corán X, 47; XVI, 36). Muhammad es mandado a unas gentes a las que Dios no ha mandado aún un Enviado (Corán XXVIII, 46; XXXII, 3; XXXIV, 44). Las otras personas a quienes el Corán confiere la dignidad de rasūl son Noé, Lot, Ismael, Moisés, Šuayb, Hūd, Sāli y Jesús. El rasūl, a diferencia del profeta, dicta leyes y va provisto de un Libro. Los personajes que en su calidad de rasūl dictaban leyes, han sido Adán, Noé, Abraham, Moisés, Jesús y Muhammad. Cf. Shorter Encyclopaedia of Islam, Leiden, 1995, pp. 469-470. En la formulación de la profesión de fe, la šahādă, que consiste de dos partes, lā ilaha illā Allāh wa Muhammad rasūl Allāh, se proclama en la segunda parte expresamente a Muhammad como rasūl Allāh. Esta profesión de fe es el primero y más importante pilar de los cinco pilares del Islam.

20. En Ms. Oc se utiliza el término șabī, para describir al muchacho jovencito.

21. El tema del huérfano y su necesidad de protección es con frecuencia (hasta en 18 ocasiones) mencionado en el Corán. Lo mismo ocurre en Ms. Oc. El propio profeta Muhammad era hijo 
Profeta, Dios lo bendiga y salve: “¿Cuánto tiempo hace que tu padre dejó el mundo?". El muchacho le contestó: "Desde hace doce días". Inquirió el Profeta, Dios lo bendiga y salve: "¿Qué hizo tu madre después de [el fallecimiento de] tu padre?". El muchacho contestó: "Ella falleció hace tres días". El Profeta, Dios lo bendiga y salve, dijo: “¿Qué pasa, / / 151r que no oigo en la ciudad el cortejo fúnebre?". El muchacho replicó: "Mi madre murió siendo forastera ${ }^{22}$ y no había para ella nadie para lavarla ni nadie para amortajarla ${ }^{23}$. El Profeta, Dios lo bendiga y salve, se volvió hacia Bilāl, su almuédano, Dios esté satisfecho con él ${ }^{24}$, y le dijo: “Vete inmediatamente a mi esposa ' ${ }^{\mathrm{A}}$ 'iša ${ }^{25}$, la madre de

póstumo, ya que su padre 'Abd Allāh ibn ' Abd al-Mutțālib ibn Hašīm (cf. E I (1979) III, p. 42, art. W. M. Watt; Ms. Oc 44 r-v, 50r) falleció, estando de viaje, antes de su nacimiento alrededor de 570 d. C.; su madre Āmina bint Wahb (cf. E I (2), I, p. 328, art. Fr. Buhl; Ms. Oc 43v-44v) falleció cuando Muhammad cumplió seis años y después fue tutelado por su abuelo 'Abd alMutțālib ibn Hašìm (cf. E I (1979) I, p. 80, art. W. M. Watt; Ms. Oc 48r-v, 50v). Sin embargo, dos años después de la muerte de su madre feneció su abuelo paterno. Este hecho le dejó desamparado a la edad de ocho años. En 578 fue acogido y tutelado por su tío Abū Țālib, el padre de su primo y yerno 'Alī ibn Abī Tâalib (cf. E I (1979) I, pp. 381-386, art. L. Veccia Vaglieri; Ms. Oc, múltiples referencias).

22. El término garïba no sólo significa 'extranjera', sino que refiere a una persona procedente de dār al-harb, 'tierra de guerra, tierra de infieles contra quienes se ha de luchar por la fe', en oposición a dār al-Salām, 'tierra de la paz, de la Umma, de la comunidad de los fieles musulmanes'. En este contexto se refiere a una persona que corresponde a todas las connotaciones negativas de la palabra, ya que, como se desprende del relato, la madre, infiel en todos los sentidos de la palabra, del muchacho actuó en contra de todos los preceptos del Islam y por esta razón, ninguna persona musulmana la podía haber lavado, amortajado o rezar por ella siquiera. Se ha elegido este personaje para realzar más el desenlace del relato y aumentar la figura y el poder del profeta Muhammad.

23. Para los ritos de la muerte, véase P. LongÁs, La vida religiosa de los moriscos, Granada, 1998, $2^{\mathrm{a}}$ ed., pp. 284-302.

24. Bilāl ibn Hamāma, esclavo abisinio, uno de los primeros en convertirse al Islam. Fue torturado por su dueño 'Umayya ibn Jalāf en La Meca para hacerle apostatar. Acompañó a Muhammad en todas las batallas. Era el primer muecín o almuédano, al-mu'addin, en efectuar la llamada a la oración, ad̄ān. Murió en 20 H/ 640 d. C. Cf. E I (1979) I, p. 215, art. W. 'Arafat; ALTABARİ, The History of Al-Tabarì, Vol VII, The Foundation of the Community, Trad. W. M. Watt, Albany, 1987, pp. 59-60. F. GuILlén Robles, Leyendas moriscas sacadas de varios manuscritos existentes en las bibliotecas nacional, real y de D. P. de Gayangos, Madrid, 1885, Edición facsímil, con estudio preliminar de Ma Paz Torres, Granada, 1994, vol. III, pp. 279-286 (Muerte de Bilal, almuédano de Mahoma). En cuanto a la función del muecín, cf. F.M. PAREJA, La religiosidad musulmana, Madrid, 1975, pp. 54-55.

25. ' 'Ā'iša bint Abī Bakr (La Meca, n. ca. 614- m. 58 H/678 d. C.). A los seis años fue desposada por su padre Abū Bakr al profeta Muhammad. El Profeta murió en 632 en casa de ${ }^{`} \bar{A}^{\prime}$ iša, su esposa preferida y fue enterrado allí mismo. Ella no se volvió a casar jamás y murió a una edad avanzada. Era muy versada en poesía e historia. Luchó infructuosamente contra ${ }^{\mathrm{A}} \mathrm{Alī} \mathrm{ibn} \mathrm{Abī}$ Țālib en la Batalla del Camello (36H/ 656 d. C.), aunque luego se reconcilió con él (cf. Corán XXIV, 11-12; LXVI, 1-5). En los Sahīh de al-Bujā̄ī y Muslim protagoniza unos trescientos hadices. Cf. E I (1979), I, pp. 307-308, art. W. M. Watt. Para una descripción de su vida, cf. AL-SAīD Al-Ŷ́ AMīlì, Al-Nisa' hawl al-rasūl, El Cairo, s.f., pp. 52-63. En Ms. Oc. hay varias referencias a ella, como fuente de un hadìt. 
los creyentes ${ }^{26}$ y dile que se vaya con este muchacho al lugar del cadáver para que la lave y la amortaje. Cuando la haya lavado y amortajado, tú nos llamarás y nosotros rezaremos por ella". Bilāl se marchó de inmediato hacia ' $\overline{\mathrm{A}}$ 'iša y le contó lo que le había dicho el Profeta. Ella cogió su manto ${ }^{27}$, se cubrió la cabeza con él y se fue inmediatamente con el muchacho. Cuando / / 151v [pasó] al lado de un grupo de las mujeres de los Aliados, que parloteaban y jugaban ${ }^{28}$ y se reían, y les preguntó: “¡Vosotras, mujeres de los creyentes! ¿Dónde está el cadáver?". Ellas le contestaron que el cadáver estaba en esa casa cerrada con cerrojo. Ella les preguntó: “¿Y por qué habéis asegurado la puerta contra ella?". Ellas le contestaron: “Te informamos de que si tú entras en la casa, te llevarás un susto de miedo. Abre la puerta y verás lo que le ha ocurrido".

${ }^{\mathrm{c}} \overline{\mathrm{A}}$ 'iša abrió la puerta y entró. La mujer tenía un olor penetrante ${ }^{29}$. [ ${ }^{\mathrm{A}} \overline{\mathrm{A}}^{\prime}$ iša] quitó el cobertor a la mujer muerta. Su cara se había vuelto negra, sus labios se habían subido y sus ojos se habían vuelto azules ${ }^{30}$. He aquí que una enorme serpiente se había / / 152r enroscado alrededor de su cuello y su boca se lanzaba a las narices de ella ${ }^{31}$. Cuando ${ }^{c} \bar{A}^{\prime}$ iša vio la serpiente, se llevó un susto tre-

26. Esta apelación, umm al-mu'minìtn, está basada en Corán XXXIII (Los partidos), 6: "El Profeta está más próximo de los creyentes que ellos; sus mujeres son sus madres. Los que tienen lazos de consanguinidad están más próximos los unos de los otros, según el Libro de Dios, que los creyentes medinies y los emigrados, [a menos que hagáis a vuestros amigos lo establecido; eso se escribirá en el Libro]". Cf. Versículo 40 de la misma azora.

27. ' 'A' iša se cubre con un sobretodo, al-ridā', un manto grande y suelto, cf. R. DOZY, Supplément aux Dictionnaires arabes, I y II, Leiden, 1881. Según Corán XXIV (La luz), 31, las mujeres deben ser recatadas y modestas, sin mostrar su cuerpo o parte de él en público. Compárese esta disposición con la descripción del estado en que ${ }^{c} \bar{A}^{\prime}$ iša encuentra a la madre del muchacho (Ms. Oc 151v).

28. Corán XLIII (El lujo), 83: “Déjales que parloteen y jueguen hasta que les llegue el Día con que se les ha amenazado".

29. En el texto original se lee "taqi $l^{\prime}$ ", 'pesado', lo que se ha traducido por 'penetrante'.

30. Los rasgos de la mujer muerta presentan los rasgos de los pecadores. Se acentúa más, sobre todo, teniendo en cuenta que hacía apenas doce días que su esposo, el padre del niño, había muerto. Por lo tanto, ella estaba en el periodo de ${ }^{c} i d d a$, periodo legalmente prescrito de espera (de cuatro meses y diez días de duración) que deben observar las mujeres musulmanas viudas, según Corán II, 234: “Quienes de vosotras mueren y dejan esposas, éstas esperarán cuatro meses y diez días. Cuando lleguen a su término, no hay falta sobre vosotros por lo que ellas hagan con su persona para volverse a casar, según está establecido. Dios está bien informado de lo que hacéis". En este caso, la madre del niño había traspasado este precepto legal.

31. El desarrollo de este hadīt contiene muestras evidentes de que la mujer era una adúltera y que la "serpiente" era su cómplice, aunque está retratado, a veces, con rasgos de serpiente cuando lo requiere este relato dotado de un 'realismo mágico' avant la lettre, como, por ejemplo, cuando se esconde, cual serpiente real, en una grieta de la pared por el efecto mágico del anillo de Muhammad, y, a veces, presenta claros rasgos antropomórficos, como cuando huye finalmente al desierto. Cf. M. Asín PALAcios, La escatología musulmana en la Divina Comedia, Madrid, Hiperión, 1981, p. 160. En este pasaje cita un ḥadīt recogido por Samarqandī (Qurra) que se refiere al castigo de los adúlteros: “Los adúlteros serán picados y mordidos por serpientes en las partes de su cuerpo donde se besaron". En Ms. Oc cómplice y castigador se funden y confunden. En el cristianismo sólo hay que pensar en Adán y Eva...jy la serpiente! 
mendo y volvió corriendo al Profeta, Dios lo bendiga y salve. Cuando el Profeta, Dios lo bendiga y salve, vio que volvía, le dijo. “QQué te pasa, que has vuelto tan deprisa?”. Ella le replicó. “¡Ay por Aquel que te envió con la Verdad! Si te explicara acerca de este asunto tan tremendo, si hubieras visto lo que he visto, tú te hubieras vuelto a toda velocidad". Cuando ella le pintó con palabras todo lo que había visto, dijo el Profeta, Dios lo bendiga y salve: "Esta mujer es una pecadora. ${ }^{\circ} \overline{\mathrm{A}}$ 'iša, toma mi anillo, vete a la serpiente y dile: “¡Éste es el ani1 lo del Profeta! ${ }^{12}$. ¡Retírate inmediatamente de esta mujer!". Entonces, la lavas y la amortajas. Si tú has sido ordenada por Dios, / / 152v te dedicas a lo que Dios haya dispuesto para ti en cuanto a esta mujer".

Cuando ${ }^{c} \bar{A}$ 'iša puso el anillo sobre la serpiente, la serpiente se fue inmediatamente a una grieta que había en la pared. Se desataron un ruido sordo y un eco como si fuera un viento tempestuoso ${ }^{33}$ que arrancara árboles. Cuando ' $\overline{\mathrm{A}}$ 'iša la [=la mujer] había lavado y amortajado, la serpiente volvió hacia ella [=la mujer], se enroscó tal como [había hecho] la primera vez y la serpiente la agitó con un meneo tremendo, que, de veras, a causa de sus meneos la casa estaba a punto de caer en pedazos y de quedarse reducida a escombros. ' $\bar{A}^{\prime}$ iša se marchó inmediatamente ${ }^{34}$. El Profeta, Dios lo bendiga y salve, y sus compañeros se ocuparon de ella y la pusieron sobre su costado derecho y la sacaron en parihuelas. //

153r El Profeta, Dios lo bendiga y salve, convocó a pleno pulmón a las mujeres y él iba [diciendo]: “¡Mujeres de los creyentes! Éste es el papel que corresponde a cada mujer que vuelve sus ojos en ira hacia su marido o hacia sus padres: que se le ponga $\mathrm{kohl}^{35}$ del kohl del infierno del día del Juicio. Cierto, el derecho del esposo sobre la mujer es como el derecho de Dios como sus sier-

32. El anillo, el sello, era el símbolo del poder, como el sello de Salomón, profeta a quien se equipara Muhammad en sabiduría y poder. Como trasfondo, está la historia tejida en torno al anillo de Salomón, que perdió su poder al serle sustraído su anillo por su mujer, quien se lo entregó a un usurpador. Éste ocupó el trono de Salomón. Al recuperar Salomón su anillo, recuperó su poder. En este pasaje de Ms. Oc, el texto hace referencia a este rasgo de poder de Muhammad, al atribuirle la posesión de un anillo con evidentes poderes sobrenaturales. Por virtud del anillo, una situación anómala vuelve a su cauce y recobra la normalidad. En el s. XIV, Ibn al-Jatịib refiere que el sultán Yūsuf I le confió su sello como prueba de confianza, apud R. ARIÉ, El reino nașrī de Granada, Madrid, 1992, p. 200.

33. En cuanto a 'un viento tempestuoso', 'rīh c āṣif véase Corán X (Jonás), 22: "...wa-ŷa' $\bar{a}^{\prime} t h \bar{a}$ rīh "āșif..." y, sobre todo, Corán XXI (Los profetas), 81: "wa-li-Sulaymān al-rīh c āṣifatan tâỳī bì-amri-hi...".

34. ' ${ }^{\prime}$ 'iša ha cumplido con su deber de musulmana en cuanto al rito funerario respecto a la preparación del cadáver y se aparta de la mujer, tan pronto como puede. Para el rito funerario, cf. Pedro LONGAS, La vida religiosa de los moriscos, especialmente en este caso, pp. 284-287.

35. El kuhl, 'kohl', es una preparación de antimonio pulverizado, usada para pintar los bordes de los párpados, en principio como método profiláctico contra enfermedades oftalmológicas. La palabra kuḥl no figura en el Corán, cf. M. 'ABD AL-B̄̄QI, Al-Mu'ŷam al-mufahras, Beirut, 1994. 
vos. $^{36}$ Si la nariz del hombre fluye con sangre o con cualquier otro exudado, luego la mujer lo ha lamido con su lengua, se cumple el derecho del esposo, esté vivo o muerto" ${ }^{\prime 37}$.

Exclamó el Profeta, la paz sea con él: “¡Mujeres de los creyentes! Esto es lo que corresponde a cada mujer que está calumniando: Él [Dios] le pide cuentas el día de la Resurrección, pegándole y le obliga a engullir / / 153v piedras del infierno el día de la Resurrección. ¡Mujeres de los creyentes! Esto es lo que corresponde a cada mujer que ha dicho a su esposo: "No hay nada bueno en ti, ni tampoco he visto nada bueno contigo". Dios hace malograr las buenas obras de ella durante setenta años. Esto es lo que corresponde a cada mujer que impone gastos a su esposo que él no puede costear: Dios la hace entrar en el infierno con los hipócritas, ninguno de los dos está contento con lo que Dios les ha dado como sustento. Ésta es la parte que corresponde a cualquier mujer que engaña con espejismos a su esposo de lo que ella tiene y que dice a su esposo: "Tú comes lo que yo tengo y te vistes de lo mío". Si ella da limosna con aquel dinero y lo gasta en el camino de Dios, Él no acepta de ella nada en absoluto y con justicia. / / 154r Esto es lo que corresponde a toda mujer que agrava su dote ${ }^{38}$ a su esposo, mientras que él está bien dispuesto hacia ella: Dios la hace entrar en el Infierno por ello. ¡Mujeres de los creyentes! ¿Acaso no veis lo que hizo la gran serpiente con esta mujer? Ésta es la parte que corresponde a la que se describió en relación con este [asunto]. ¡Ay de las que son negligentes con sus oraciones!

Cuando se enterró a la mujer y con ella la gran serpiente adherida a su pecho, se elevaron sobre la tumba llamas y humo. El muchacho comenzó a llorar y a dar alaridos, mientras estaba al lado de la tumba de su madre. Le alcanzaron las llamas y el humo y empezó a decir: “¡Mi Señor, mi Socorro, mi Anhelo, mi Dueño, // 154v Quien habita en el Cielo, Quien contesta al que

36. Para los derechos de los hombres sobre las mujeres, ej. Corán IV (Las mujeres), y especialmente para este caso Corán IV, 34 .

37. C. López-Morillas, Textos aljamiados sobre la vida de Mahoma: El Profeta de los moriscos, Madrid, 1994, pp. 107-110, subcapítulo V-b: Los derechos del marido y la mujer, p. 108: "Y fue recontado por el annabī ' $l m$ que si el marī do le corriese sangre por el un fornillo de las narices y por el otro podre, que aún no le pagaría el marī $\underline{d}$ e el derecho que tiene sobrella".

38. Según los preceptos del Islam, al casarse, el hombre ha de dar a la futura esposa una dote, mahr, o așdiqa, generalmente una parte sustancial de dinero y/u otros bienes de valor, cuya cuantía está previamente convenida por los dos tutores legales $(w \bar{a} l \bar{\imath})$, uno por parte de la novia y otro por parte del novio. La dote ha sido previamente pactada y resignada por un notario $\left({ }^{c} a d \bar{u} l\right)$ en el contrato matrimonial erigido a tal efecto. En Ms. Oc hay tres referencias a la dote (Ms. Oc 42v (Adán), 139r (mujer violada), 154r (mujeres). Para la dote, ej. Corán IV (Las mujeres), 4: "Dad a las mujeres, espontáneamente, sus dotes. Si ellas os favoreciesen dándoos, espontáneamente, algo, comedlo a gusto". C. LóPEz-MoriLlAs, Textos aljamiados sobre la vida de Mahoma: El Profeta de los moriscos, p. 69, donde se recoge un hadīt acerca del casamiento de Āmina: "Dišo Wahb [el padre de Âmina]: "Ye Abā al-Hāriz, mi hija seya alhadiya a ti y a tu fijo, sin assidaq adelantado ni aplazado. Ante daremos yo y su madre de nueso alçado con quella vaya onrada a su marido". 
Lo invoca! ¡Quien hace que el alba apunte, Quien hizo de la noche descanso y del sol y de la luna cómputo! ${ }^{39}$. Perdona a mi madre querida y amiga, que es [ahora] para mí una tumba. Si yo estaba perdido, ella me buscaba; si yo tenía hambre, ella me alimentaba; si yo tenía sed, ella me dio de beber; si yo estaba desnudo, ella me abrigaba; si yo enfermaba, ella me lloraba. Quien puso su vientre como casa para mí, sus pechos como alimento para mí, sus cabellos como cobija para mí, ¡libérala del fuego abrasador! Cierto, Tú eres Quien todo lo oye, Quien todo lo sabe, sé condescendiente conmigo, Señor".

El Profeta, Dios lo bendiga y salve, dijo: “Esto es el ruego. ¡Tú, Quien basta, Quien creó la noche y el día, y dio forma a la creación de las cosas! / / 155r ¡Perdona a esta mujer, por la Verdad de las aleyas del Corán!”. Entonces, Dios la tuvo en Su misericordia, como favor al chico y en respuesta a la petición del Profeta, la paz sea con él. Dijo el Profeta, Dios lo bendiga y salve: "Por Quien me ha enviado con la Verdad, como anunciador de la buena nueva y como predicador. No se libera a la grey de la tumba hasta que Él haga descender sobre ella a Gabriel, la paz sea con él, con el perdón para ella y para la salvación del Infierno".

El vulgo contempló a la gran serpiente que se iba huyendo al desierto, su rostro se atezó por el calor infernal ${ }^{40}$. Mientras, la misericordia divina descendió sobre la mujer, junto a los bienes de los Jardines de la Delicia ${ }^{41}$.

\section{EL HADIT DE “EL PROFETA MUHAMMAD Y EL NIÑO HUÉRFANO” EN LA LEYENDA DEL ALCÁZAR DE ORO (CONTENIDO EN LOS FOLIOS 58V-63V DEL MANUSCRITO ALJAMIADO-MORISCO II/3226)}

Se trata de un hadìt encontrado en el manuscrito aljamiado-morisco II / 3226, conservado actualmente en la Biblioteca del Palacio Real de Madrid. El manuscrito procede de Ricla (Aragón) ${ }^{42}$, donde fue hallado en el hueco

39. El texto en cursiva corresponde a una cita trunca de Corán VI (Los rebaños), 96: “Quien hace que el alba apunte, Quien hizo de la noche descanso y del sol y de la luna cómputo. Esto es lo que ha decretado el Poderoso, el Omnisciente". En Ms. Oc las citas coránicas son muy frecuentes, aunque pocas citas son aleyas completas, las más truncas o, incluso, interrumpidas por una parte del texto. En la Tesis doctoral se ha dedicado dentro de los Estudios un capítulo específico para las aleyas del Corán, encontradas en Ms. Oc.

40. Corán XIV (Abraham), 51: "sus calzones serán de alquitrán y sus rostros estarán cubiertos de fuego".

41. J. Cortés, El Corán, Madrid, 1984, p. 184: 'Los Jardines de la Delicia' 'ŷannāt al-na'īm' forman parte del paraíso y son mencionados siete veces en el Corán (V, 65; X, 9; XXII, 56; XXXI, 8; XXXVII, 43; LVI, 12; LXVIII, 34). J. VerNET, El Corán, Barcelona, 1998 (reedición) traduce el término por 'jardines de ensueño'; J. BERQUE, Le Coran, Paris, 1995, p. 131: 'jardins de bonheur'; 'Abdullah Yūsuf 'Alī, The Holy Qurān, Beltsville (Maryland, USA), 1998. p. 269: 'Gardens of Bliss'.

42. Acerca de Ricla, cf. P. MADOZ, Diccionario geográfico-estadístico-histórico de España y sus posesiones de Ultramar, Tomo XIII, Madrid, 1849, pp. 469-470: "Ricla está situado a 8 leguas de 
debajo de un pilar de una casa ${ }^{43}$ y data del s. XVI; está escrito con letra magrebí; el papel presenta una filigrana - una mano muy cuidada-bien visible. El manuscrito contiene una colección de hadices y lleva por título La leyenda del alcázar de oro. Otro de ellos se ha titulado El profeta Muhammad y el niño huérfano.

\section{Observaciones}

Los folios del manuscrito II/3226 no son todos iguales, debido al hecho de que varias manos han trabajado en el manuscrito y que dicho manuscrito parece ser más bien un manojo de manuscritos varios; se observa que la temática es bien diversa. Lo que interesa ahora es el hadit que comienza en Ms. II/3226, fol. 58v, $11^{44}$ y que termina en fol. 63v, 5, el hadīt de El Profeta Muhammad y el niño huérfano.

/ / 58v, 11 En nombre de Dios, el Clemente, el Misericordioso. El hadiz del profeta Muhammad, / Dios lo bendiga y salve. Es contado por nuestros / sabios que, estando nuestro Profeta Muhammad, Dios / / 59r, 1 lo bendiga y salve, un día con su compañía (=sus compañeros), vínole a la mente/ el hecho ${ }^{45}$ del

Zaragoza (part. Jud. de Almunia), en terreno llano, próximo a la ribera del río Jalón...clima templado...el terreno es de la mejor calidad y muy fértil su huerta que fertiliza el Jalón. Es población de gran antigüedad, célebre en la historia de la España romana bajo el nombre de Nertóbriga. Ptolomeo la mencionó...Era mansión del Itinerario Romano...Ganóla a moros el rey D. Alfonso I de Aragón, año 1120. En 1357 fue dado al conde D. Enrique para sí y sus descendientes. El rey D. Felipe II la erigió en condado que confirmó D. Felipe IV ...Es patria del célebre escritor árabe Abdallá, vulgarmente llamado Alrribli".

43. En la primera hoja de guarda, sin numerar y sobre papel más reciente que el Ms. II/3226, se puede leer una única y breve anotación escrita con letra decimonónica y con tinta negruzca: "Libros moriscos hallados / en un pilar de una/ casa de Ricla". En el interior de la contratapa hay un sello grande con el escudo real; encima se lee '2. G. 6'; debajo del escudo, en una cartela del pedestal que sostiene al escudo se lee 'Biblioteca / del / Rey N Neñor'. Bajo dicho pedestal se lee 'IV G 4'. Hay pegado debajo del sello grande un pequeño sello dentado con la numeración inscrita '3226'. En cuanto al Ms. II/ 3226, Incipit: Bismi illahi irrahmāni irrahīmi/ El al hadīt del alcazar del oro y la storia del culuebra con Alī bnu Abī Ta [...]bi. / / Excipit: Bismi illahi irraḥmāni irraḥimi / Acabatolo para los que se orinan/ en la cama y es tomaras //.

44. Cada uno de los folios que contienen este hadīt lleva trece renglones de escritura con grafía magrebí. En este manuscrito morisco del s. XVI, el ductus es algo torpe, como de una persona no del todo habituada a escribir en árabe cotidianamente; presenta rasgos habituales en otros mss. moriscos, encabalgamiento de palabras, la palabra se corta donde sea necesario, aunque sólo sea para una letra, irregularidad en la unión de palabras, sean sustantivos, pronombres o preposiciones, la letra ' $p$ ' es representado por una ' $b a$ ' con 'tanwīn', etc. Sorprende el descuido con el que se ha escrito el nombre del Profeta, Muhammad. El hadìt de El profeta Muhammad y el niño huérfano del Ms. II / 3226 va cuidadosamente vocalizado, con la misma tinta negra. No presenta reclamos ni glosas ni notas marginales.

45. Dice el texto de Ms. II/3226, fol. 59r, 1-2: "binulā adāmiāntā/ dāl-fŷu dāl-dunya". Cf. C. LóPEZ-MoRILlAs, Textos aljamiados..., p. 151, 'ad(a)': “a”...Arag.[onés] ant.[iguo]. En Ms. II/3226 figura ' $a d \bar{a}$ ' unido directamente a la palabra miāntā. Se puede interpretar la frase 'se puso a pensar en [la fugacidad d]el mundo'. 
mundo y de cómo era el poder $[i ?]^{46}$ que tiene [sobre] el/ otro mundo y lloró amargamente. Estaban con él sus / compañeros, Dios esté satisfecho con ellos, y les preguntó: “¿Quién de vosotros viene conmigo/ por la ciudad? Haremos mercado con las/ gentes y las gentes con nosotros, y mercado haremos, con Dios, mercado que nunca se ha hallado". Le dijeron: / "Enviado de Dios, ¿qué negocio haremos con las gentes y / las gentes con nosotros?". Él les dijo: "Les saludaremos / y ellos devolverán el saludo a nosotros y serán iguales/ sus enhorabuenas a las nuestras. Quien se/ muestre soberbio, [esto] irá contra él y si no nos devolverá el saludo, / Dios le anotará por esto trescientos setenta pecados / / 59v, 1 y Dios le borrará ciento setenta mil buenas obras. / Nosotros daremos nuestros pecados y ellos nos darán/ sus buenas obras". Ellos le dijeron: "Enviado de Dios, ¿qué negocio/ concertaremos con Dios, el cual nunca se ha hallado?". / Él les contestó: "Si halláramos algún [tachón en ms]/ huérfano, lo acogeremos y si halláramos / algún cautivo, lo rescataremos; si encontráramos algún hambriento,/ le daremos a comer y si hallásemos algún desnudo,/ lo hemos de vestir. Si halláramos algún herido, le ayudaremos. Si / halláramos alguna (niña) pobre, tenemos que casarla [siendo su tutor]". / Mientras, el profeta Muhammad, Dios lo bendiga y salve, / y sus compañeros andaban por la ciudad. De repente, había un niño que lloraba/ desconsoladamente y tenía su mano contra su mejilla y sus / / 60r, 1 lágrimas le corrían por las mejillas. Le dijo el profeta Muhammad,/ Dios lo bendiga y salve: "Mancebo, ¿por qué lloras?". Le dijo: "Enviado/ de Dios. Lloro por la orfandad". Le dijo [el Profeta]: "Hijo, ¿cuánto [tiempo] hace que murió/ tu padre?". Le contestó [el mancebo]: "Hace doce días". [El Profeta le preguntó:] “¿Y tu madre?”. Le contestó [el mancebo]: "Hace tres / días". Le dijo el Profeta Muhammad, Dios lo bendiga y salve:/ "Mancebo, no ocurre nada en esta ciudad,/ que yo no sé". [El mancebo le] contestó: "Enviado de Dios, mi madre era extranjera y no hay/ quien la bañará ni la amortajará ni quien haga la azala por ella". A punto se volvió/ el Profeta Muhammad, Dios lo bendiga y salve, a Bilāl ibn/ Hamāma y le dijo: "Bilāl, vete y di a ' $\bar{A}$ 'iša, la madre de los / creyentes, que vaya con este mancebo adonde el cadáver de la madre de este mancebo y que la bañe y la amortaje. Esto/ es lo que debemos hacer". Se fue / / 60v, 1 Bilāl a la casa de ' $\overline{\mathrm{A}}$ 'iša, Dios esté satisfecha con ella, y la hizo saber/ aquello y ${ }^{c} \bar{A}$ 'iša tomó su manto y se lo puso sobre su cabeza/ y se fue con el mancebo adonde estaba el cadáver. Ella vio un gran/ grupo de mujeres en una puerta, que reían, jugaban y / cantaban, y les dijo: "Mujeres, ¿dónde está aquí el cadáver?". / Le dijeron: "En aquella casa que está cerrada". Les dijo:/ "Mujeres de los creyentes, ¿por qué .../ del cortejo fúnebre y por qué está cerrada su puerta?". Le dijeron/ las mujeres: "Si te lo hacemos saber, te espantarás / muchísimo. Empuja la puerta y verás una gran/

46. Dice el texto de Ms. II/3226, fol. 59r, 2: "erašubulbimiāntu kāldāla / uturu adunya”. Cf. O. HEGYI, Cinco leyendas y otros relatos moriscos, C.L.E.A.M 4, Madrid, 1981, pp. 213 y 359 'volvimiento'= 'poder'. 
maravilla de tu Señor, que ha bajado ${ }^{47}$ sobre el cadáver. / ' $\overline{\mathrm{A}}$ 'iša abrió la puerta $\mathrm{y}, \mathrm{ay}^{48}$, tenía la mujer muerta negra/ la cara, blancos sus ojos, gruesos sus // 61r, 1 labios y tenía una culebra muy gruesa/ enrollada en su pescuezo y la boca de la culebra [pegada] a las narices/ de la [mujer] muerta. Cuando vio aquello, se maravilló mucho de su Señor / y se volvió apresuradamente huyendo hasta donde estaba/ el profeta Muhammad, Dios lo bendiga y salve. Le dijo [el Profeta]: “¿Qué (cosa)/ es que te veo apresurada?”. (“Á'iša) le dijo: “Profeta de Dios, ipor Aquél que/ te envió con la Verdad! Yo he visto un hecho muy grande que / me ha espantado". Le contó todo lo que había visto. Al punto le dijo [el Profeta]:/ “Pecadora fuiste ${ }^{49}$ para el Señor de todas las cosas!/ Madre de los creyentes, toma este anillo mío y vas con él/ a la culebra y dile: “Éste es el anillo del profeta Muhammad, Dios lo bendiga/ y salve. jApártate de este cadáver que así/ es mandado por parte de nuestro Señor! Cuando oyó / / 61v aquello la culebra, se apartó del cadáver y se adentró/ en una grieta que estaba en la pared y oyó de ello un ruido como/ ruido de aire muy fuerte. Cuando fue bañada y amortajada/ la mujer, tornó a salir la culebra de donde estaba / y se revolvió en su pescuezo y puso su boca en las/ narices de la mujer y le estremeció un estremecida [=estremecimiento]/ que la volvió del otro costado. Al punto mandó 'Ā'iša, Dios esté satisfecho/ de ella, a Bilāl que pregonase la azala y el Mensajero/ de Dios fue a hacer la oración por ella [=la mujer] y vio la grandeza/ de su Señor. Mandó sacarla en una tabla y dijo. “iMujeres / de los creyentes! ¡Éste es el galardón de toda/ mujer que torna sus ojos y contesta a su marido! Sabed, / mujeres de los creyentes, que el derecho de Dios sobre/ sus siervos es su querer matarlo o darle vida. Es / en Su querimiento (=voluntad). Sabed, mujeres de los creyentes que éste/ es el galardón de toda persona que torna airados / sus ojos a su padre y a su madre: saldrá cubierta de $\mathrm{kohl}^{50}$ / en el día del Juicio con el kohl del Fuego./ ¡Mujeres de los creyentes! Éste es el galardón/ de toda mujer que malsina ${ }^{51}$ (=calumnia): revivifícala Dios el día/ del Juicio con los renegados. Este es el/ galardón de toda mujer que dice a su marido: "Nunca he visto/ contigo bien ninguno". Dios no recibe de ella la limosna, / ni la oración ni el ayuno. Éste es el galardón de toda/ mujer que impone a su marido una despensa

47. C. López-Morillas, Textos aljamiados..., p.161: deballar: bajar.

48. En el texto aljamiado Ms. II/3226, fol. 60v, 12: “i bāuš ”, "y veos”. Cf. O. HegYI, Cinco leyendas y otros relatos moriscos..., p. 358, 'veo os' "he aquí"; A. VESPERTINO RODRíGUEZ, Leyendas aljamiadas y moriscas sobre personajes biblicos, C.L.E.A.M 6, Madrid, 1983, p. 394, 'veos' "he aquí que". Aquí hemos traducido el término por " $a y$ ".

49. Probablemente se trata de una mala 'lectura' bi-l-samā $>$ por parte del copista o de una transmisión defectuosa del relato en Ms. II/3226, fol. 61r, 9: 'yābbākadura fuāštā bbarālšannur'. La versión de Ms. Oc 152r (q. v.) parece más coherente con el contexto.

50. En Ms. II/ 3226, fol. 62r, 4-5: "alkholada", que se ha traducido por "cubierta de kohl (=antimonio)".

51. O. Hegri, Cinco leyendas y otros relatos moriscos..., p. 325: Malsiknar, 'calumniar, hablar mal'... Variante del ant. malsinar... 
(=gasto), que él no podrá/ ganarla ${ }^{52}$. ¡Mujeres de los creyentes! Habéis / / 62v visto esta culebra que Dios no ha mandado sobre / esta mujer, sino ver que no se ocupaba $^{53}$ de la oración/ ni de la limosna ni del ayuno ni de ningún bien/ hecho. Cuando fue enterrada la mujer, se levantaron/ sobre su fosa humo y llamas. Vino el man-/cebo y se puso a llorar al lado de la fosa de su madre y decía: "¡Señor, Aquel que puso morado-/ res en los cielos y en la tierra, Mayor de/ los Mayores! ¡Perdona a mi madre, la piadosa por/ mí! Si me absentaba, me buscaba; si tenía hambre, / me daba de comer; si enfermaba, me lloraba; si iba desposeído, me vestía y me cubría. ¡Señor, perdona a mi madre! ¡Aquel, que puso a mí en su vientre y barriga/ / 63r y sus faldas abrigadora[s] para mí! ¡Fuérzala y sácala/ del tormento del Gehena! ¡Que Tú eres oidor del ruego/, el más Piadoso de los piadosos!". Le respondió el profeta/ Muhammad, Dios lo bendiga y salve, y él dijo: “¡Responde/ al ruego de este mancebo, Medicinador de todas/ las cosas, Aquel que formas la noche y el día y haces / correr los ríos y fraguas las criaturas sin semblanza!”. Dijo 'Umar ibnu al-Jaṭ țāb, Dios esté satisfecho de él,: “¡Respondedor a toda la Noche, Glorificado en todo lugar,/ Aquel que/ Tú eres Semblanza, no puede asemejarse Tu/ semblanza persona ninguna que fue en el mundo ni será! Perdona/ a su madre del mancebo éste y líbrala del tormento de su fosa/ [tachadas las líneas 12-13 en ms.] / / [tachadas las primeras palabras] del Gehena". Así/ Dios la perdonó y la libró del tormenta de su fosa y del Gehena/ por el ruego de su hijo y del profeta Muhammad, Dios lo bendiga y salve, y por el ruego de `Umar bnu al-Jat țāb, Dios esté satisfecho de él. Aquí se acaba el ḥadīt. / /

\section{COMENTARIO}

Con estas palabras termina el hadīt de El profeta Muhammad y el niño huérfano en Ms. II / 3226. Como se desprende de la lectura del relato piadoso redactado en el s. XVI, al comparar la recensión con la del Manuscrito mudéjarmorisco de Ocaña, hay bastantes variantes. Uno de las más sorprendentes es la aparición en escena de 'Umar al-Jat ț āb, el segundo califa ortodoxo (634-642 d. C.), en el relato aljamiado tardío. Sin embargo, el relato carece de la fluidez narrativa y los detalles que presenta el Ms. Oc.

Leyendo el texto detenidamente, sobre todo Ms. Oc fols. 153r-154r, cabe la hipótesis que este relato de El profeta Muhammad y el niño huérfano estaba concebido para establecer claramente los deberes de las mujeres respeto a su vida conyugal e incluso, en un aparte, casi fuera del propio hadìt, se apela exclusivamente a las i“mujeres de los creyentes"! Hay alusiones al mahrr, la dote, conditio

52. En Ms. II / 3226, fol. 62r, 11-13 se lee: “Éste es el galardón de toda/ mujer que costará en ira a su marido con despensa que él no pod-/ rá ganarla".

53. En Ms. II/ 3226, 62v, 2: 'kuraba', 'curaba'. 
sine qua non tan importante al contraer un matrimonio musulmán, que no se ha de agravar una vez pactados los acuerdos, y se declara que "el derecho del esposo sobre la mujer es como el derecho de Dios sobre sus siervos" (fol. 153r Ms. Oc).

Los aspectos doctrinales a destacar son la intercesión del profeta Muhammad para la salvación de la madre muerta y la clemencia de Dios respeto a los pecadores, incluso tratándose de faltas tan graves como la transgresión de las leyes y las disposiciones acerca de los deberes conyugales, incluso después de la muerte. Hay una descripción del ritual previsto para preparar el cadáver y cómo el Profeta indica a su propia esposa la forma de actuar. Otros aspectos doctrinales importantes a destacar son el tema de la absoluta obediencia al profeta Muhammad, su esposo, por parte de ' ${ }^{\prime} \bar{A}$ 'iša, paradigma de virtud canónica femenina; su recato, poniéndose su manto antes de salir a la calle y saliendo de casa solamente a petición de su esposo, el Profeta, y su seriedad frente a las rientes y parlanchinas mujeres del pueblo, sentadas en la calle. Su pío comportamiento conyugal está en total y absoluta oposición con el comportamiento liviano y lascivo de la mujer profana. Todas estas oposiciones en cuanto a comportamiento sirven para aumentar la veneración por los personajes píos y escarmentar a los fieles ante posibles flaquezas en su conducta humana. Pero la descripción de ambos aspectos tienen un fin primordial: ensalzar la grandeza de Dios al otorgar a los hombres Su clemencia.

El relato presenta una perfecta composición narrativa: a. Presentación de los hechos mediante una descripción de los protagonistas principales, el profeta Muhammad y el niño huérfano, y sus circunstancias (el Profeta deambulando en la medina, el niño llorando su orfandad); y una posterior presentación mediante la descripción de los personajes secundarios, los compañeros del Profeta, Bilāl, ' $\bar{A}$ 'iša, las mujeres del pueblo como si de un coro griego se tratara, y la circunstancia mayor, es decir, el hallazgo macabro de la madre difunta, presentada en una situación indecorosa con la sierpe, por parte de ${ }^{c} \bar{A}^{\prime}$ iša. $b$. Núcleo, la intervención del Profeta y el poder de su anillo. c. Desenlace, los ruegos desesperados del niño y la posterior intercesión de Muhammad ante Dios para salvar a la madre y, de este modo, obtener la clemencia de Dios. Dios, Misericordioso, otorga el perdón a la madre, a pesar de su condición de gāriba y pecadora.

Tampoco faltan ingredientes de suspense: la serpiente ${ }^{54}$, feroz y amenazante, enroscada alrededor del cuello de la madre muerta; la valentía de ' $\bar{A}^{\prime}$ iša

54. A mi juicio, en este relato se trata de un vergonzoso adulterio, ya que la serpiente está relacionada con la infidelidad, la lascividad y la promiscuidad masculina. Quizás, esta suposición está más en acorde con los preceptos coránicos en cuanto al comportamiento de la mujer tras la muerte de su esposo, ej. C II, 234. Para el tema de la serpiente y el incesto, cf. D. HERNÁNDEZ DE LA FuENTE, Elementos Órficos en el Canto VI de las Dionisiacas: El mito de Dionisio Zagreb en Nono de Panópolis, en 'Ilu, revista de ciencias de las religiones, vol. 7 (2002), pp. 28-29. Sin embargo, en su excelente Introducción, María J. Viguera apunta a un posible caso de lesbianismo que subyace en este relato, cf. F. CORRIENTE CÓRDOBA, Relatos píos y profanos..., p. 43. 
al atreverse a colocar el anillo del Profeta sobre la malvada serpiente; el poder del anillo de Muhammad sobre la terrible bestia y la casa que, en la lucha por el poder, por poco se derrumba ante la forzada marcha del iracundo reptil; finalmente, la huida avergonzante del infeliz intruso tiznado hacia el desierto ante la mirada de los circunstantes.

Los diálogos transcurren en un tono coloquial y muy vivo, adecuado a cada momento y a los personajes, mientras la descripción de los lugares, la casa, la calle, la medina, la fosa (en su cementerio), es absolutamente reconocible y aplicable a cualquier hábitat musulmán y su entorno, por lo tanto, se adapta perfectamente a las circunstancias diarias pertenecientes a cualquier asistente de la lección de exégesis coránica. Que la casa de la madre muerta muestra una grieta en la pared no debió de haber extrañado a ningún oyente fiel, porque, probablemente, la suya también tendría alguna que otra grieta en alguna pared, pero, al mismo tiempo, es un ingrediente más de los denigrantes en torno a la mujer, que, además, es una gāriba, una extranjera y, seguramente, infiel. El realismo presente en todos estos relatos facilita la identificación de los fieles con los protagonistas que no confundían los personajes paradigmáticos como Muhammad y ' ${ }^{\prime}$ 'iša con los personajes profanos, el hombre y la mujer de carne y hueso como ellos mismos y, por lo tanto, expuestos e inclinados a transgredir alguna norma, hadd.

Sin embargo, para su consuelo, tan necesitado en los tiempos de angustia que vivían los fieles musulmanes y, sobre todo, los mudéjares-moriscos de la Península Ibérica, y como les enseñaba un relato como el Hadît de Muhammad y el niño huérfano, Dios es Clemente, Misericordioso.

\section{EL METALENGUAJE DE LOS RELATOS ISLÁMICOS}

Todos estos relatos, aparentemente tan ingenuos, contienen un profundo metalenguaje que los fieles musulmanes identifican y sienten como enteramente suyo, sin palabras alusivas explícitas: reconocen y conocen la condición del Profeta, su orfandad a edad temprana; la condición de ${ }^{\mathrm{C}} \overline{\mathrm{A}}$ 'iša, la esposa más querida del Profeta, la única de todas sus mujeres que se casó siendo virgen y que, después de su muerte, nunca se volvió a casar, su valentía ya mostrada en la Batalla del camello y su sabiduría; Bilāl, el primer almuédano, tan fiel y entregado a Muhammad y su entorno. Los fieles conocen la maldad del Šayțān, el diablo, encarnado en este relato en la piel de serpiente, tiznado, huyendo ante el poder de Dios; el poder de Dios está simbolizado por el anillo que lleva el Profeta, al igual que el anillo de Salomón, el más sabio y más poderoso de los profetas anteriores a la venida de Muhammad. Los musulmanes conocen y reconocen a los compañeros del Profeta y los méritos de muchos de ellos. Las connotaciones inherentes a cada personaje y a cada situación son muy variadas y amplias, sin que haga falta hacer alusiones específicas, porque en esto consiste precisamente el metalenguaje religioso que subyace bajo cada palabra de estos 
relatos. Quizás reside en este metalenguaje el poder cautivador de estos relatos y hadices de los profetas y de los sabios y la razón de su centenaria transmisión, tanto oral como escrita, a través del mundo musulmán, aparte de su alto valor doctrinal. Los desenlaces de los relatos muestran la humildad y el arrepentimiento que deben tener sus siervos ante la sabiduría de Dios. La fe religiosa de los musulmanes reside en la absoluta confianza en Dios Clemente y Misericordioso, como en este hadìt de El profeta Muhammad y el niño huérfano.

\section{RESUMEN}

En este trabajo se presenta el hadìt de El profeta Muhammad y el niño huérfano extraído del Manuscrito mudéjar-morisco de Ocaña, hallado en una pared de la Casa de la Encomienda en Ocaña (Toledo) en 1969. Dicho manuscrito, anónimo, escrito en árabe andalusí y datado alrededor de 1450 d.C., ha sido traducido, estudiado y editado por la autora en 2001 como objeto de su Tesis doctoral. El hadìt de El profeta Muhammad y el niño huérfano se ha cotejado con una versión aljamiada encontrada en el Ms. II/3226, aljamiado, anónimo, datado en el siglo XVI, y actualmente conservado en la Biblioteca Real del Palacio Real en Madrid. El texto aljamiado de Ms. II/3226 ha sido transcrito en castellano moderno por la autora de este trabajo y se presenta en conjunto con el texto del manuscrito mudéjar-morisco de Ocaña. Posteriormente, se hace un breve análisis del hadît y su razón de ser en las postrimerías de la presencia musulmana en España. El texto árabe-andalusí del manuscrito mudéjar-morisco de Ocaña parece ser anterior a la versión aljamiada de Ms. II/3226.

Palabras clave: manuscrito, mudéjar, morisco, Ocaña, aljamiado, Muhammad, huérfano, anillo.

\section{ABSTRACT}

In this essay we present an hadit about "The Prophet Muhammad and the orphan boy", extracted from the "Mudejar-morisco Manuscript of Ocaña" found hidden in a wall of the "Palace of the Encomienda" in Ocaña (Toledo, Spain) in 1969. This manuscript has been traduced, studied and edited by the author of this paper for the obtention of her Master Degree at the Universidad Complutense de Madrid in 2001. The Mudejar-morisco Manuscript of Ocaña is written in the Spanish Arabic dialect, anonymous and without date, probably composed around 1450 A.D. The hadit of "The Prophet Muhammad and the orphan boy", written in Spanish Arabic dialect, has been compared with an aljamiado version of Manuscript II/3226, aljamiado, anonymous, dated XVIth century and actually conserved in the Royal Library of the Royal Palace in Madrid (Spain). The aljamiado version has been translated into modern Spanish by the author of this paper and is compared with the text of the mudejar-morisco 
manuscript of Ocaña, written in the Spanish Arabic dialect text of mid XVth century. The essay offers a short study of the contents and the purpose of these texts, especially at the looming end of Islamic culture in XV-XVIth centuries' Spain. The Spanish Arabic text of the hadit might be older than the aljamiado text.

Key words: manuscript, mudejar, morisco, Ocaña, aljamiado, Muhammad, orphan boy, ring. 